\title{
Isolation and identification of fungi from apparently healthy and diseased Clarias gariepinus from freshwater in Zaria, Kaduna State, Nigeria
}

\author{
Salawudeen M. T. ${ }^{1 \star}$, Kazeem H. M. ${ }^{1}$, Raji M. A. ${ }^{1}$, Oniye S. J. ${ }^{2}$, Kwanashie C. N. ${ }^{1}$ and Ibrahim M. J. ${ }^{3}$ \\ ${ }^{1}$ Department of Veterinary Microbiology, Faculty of Veterinary Medicine, Ahmadu Bello University Zaria, Nigeria. \\ ${ }^{2}$ Department of Biological Sciences, Faculty of Sciences, Ahmadu Bello University Zaria, Nigeria. \\ ${ }^{3}$ Department of Veterinary Public Health and Preventive Medicine, Faculty of Veterinary Medicine, Ahmadu Bello \\ University Zaria, Nigeria.
}

Accepted 8 March, 2017

\begin{abstract}
Fish and fishery products have been documented as a major source of food-borne pathogens of which bacteria and fungi play major roles. The fungal organisms contaminating apparently healthy and diseased Clarias gariepinus in Zaria, Kaduna State was investigated. The standard mycological procedure revealed isolation of similar fungal organism been associated with apparently and diseased fish. The fungal organism isolated from the skin and gills of diseased fish were 26 (13.1\%) Aspergillus fumigatus, 25 (12.6\%) A. flavus, 36 (18.1\%) Aspergillus niger, 37 (18.7\%), Penicillium species, 14 (7.1\%) Mucor species, 4 (2.0\%) for Rhizopus species, $14(7.1 \%)$ Trichophyton sp., and $42(21.2 \%)$ yeast isolates. While the gills and the skin of apparently healthy $C$. gariepinus yielded 73 (18.6\%) Aspergillus fumigates, 53 (13.5\%) A. flavus, 57 (14.5\%) A. niger, $1(0.25 \%)$ A. parasiticus, 45 (11.55\%) Penicillium sp., 38 (9.7\%) Mucor species, 6 (1.5\%) Rhizopus sp. and $119(30.4 \%)$ yeast. There was no statically significant $(P>0.05)$ difference in isolates from skin and gills. All the fish were positive for multiple fungal isolates. The diseased $C$. gariepinus were characterised wih skin ulcer, fin rot and tail rot. The study showed the majority of the isolates belonging to Aspergillus sp. and potential aflatoxin producers. Isolation of pathogenic fungi from skin and gills of $C$. gariepinus from cultures, meant for human consumption is alarming which can be a source of fish born infections. Attention should be paid to fish health in the culture so as to conserve public health and safeguard the farmer's investment.
\end{abstract}

Keywords: Clarias gariepinus, diseased, apparently healthy, fish, yeast and filamentous fungi.

*Corresponding author. E-mail taiwohussain@gmail.com. Tel: +23407057349926.

\section{INTRODUCTION}

Nigeria is blessed with over 14 million of hectares of reservoirs, lake, ponds and major rivers which account for about $12.4 \%$ of the total surface area of the nation (Olaosebikan and Raji, 1998). These water bodies are capable of producing over 980,000 metric tonne of fish annually (FDF, 2007). These bodies of water in addition to aquaculture and fish culture constitute sources of fish supply from inland fisheries of Nigeria (Adesulu et al., 2004).

The disease is one of the most important and universally recognized constraints of fish production in
Nigeria posing threats to the commercial success of aquaculture and fish farming (Nkemakolam et al., 2011). Diseases of fish may be of viral, bacterial, Chlamydia, fungal, rickettsial or parasitic origin.

Fungal diseases are the most serious cause of losses in aquaculture (Meyer, 1991) being the most recurrent type of disease problem in all types of aquaculture facilities resulting in considerable economic losses in the industries (Meyer, 1991). Many of the fungi that affect fishes are considered opportunists, attacking the fishes when they are stressed or immune-compromised, or they 
may be secondary to bacterial or viral infections, or when they have lost their mucus protection because of trauma or excessive handling or due to inadequate nutrition (Roberts, 1989; Quiniou et al., 1998). Many fungal organisms infect fish causing spoilage leading to huge financial losses either in term of cost of medication to treat or outright loss of the fish to diseases; while some are of zoonotic potential, causing diseases in animal and human, and many may produce metabolites that can cause deleterious effect in man and animals (Douglas et al., 2000).

Many fungal species can spoil food products or produce mycotoxins or both (Anderson and Thrane, 2006). Fungal mycotoxins produce a wide range of injurious effects in animals, in addition to causing food borne hazards to humans and these mycotoxins may result in decreased productivity, immune suppression and chronic damage to vital tissues and organs of animal and humans (CAST, 2003). Some of the fish pathogens are of public health importance, while others are part of the microbiota of both Clarias and Tilapia (Olojo et al., 2010, Efuntoye et al., 2012). Hence it is necessary to identify fungal organisms associated with diseased and apparently healthy fish in the target area.

\section{MATERIALS AND METHODS}

\begin{abstract}
Samples
Seventy-eight diseased Clarias gariepinus of various sizes with the ulcer, fin rot, and tail rot and one hundred and seventy eight (178) apparently healthy $C$. gariepinus were sourced from integrated fish farms. The fish were raised in concrete ponds and fed on commercial feeds. Individual fish was collected using a sterile polyethene bag and transported within an hour of the collection to the Department of Veterinary Microbiology Diagnostic Laboratory, Ahmadu Bello University. Skin scrapings, lesions scrapings and gills swabs were collected from diseased and apparently healthy $C$. gariepinus by first disinfecting individual fish with cotton wool soaked in $70 \%$ ethyl alcohol. Skin scrapings were collected by scraping the lesions and the surrounding skin of diseased $C$. gariepinus and the skin of apparently $C$. gariepinus using sterile scalpel blade into sterile Petri dishes. The operculum covering the gills was raised up then sterile swab rolled around the gills.
\end{abstract}

\section{Fungal isolation and identification}

Each sample was inoculated onto sabouraud dextrose agar (composition gm/ltr-mycological peptone-10, agar-16, dextrose-40, ph $5.6 \pm 0.2$ ) incorporated with chloramphenicol (to inhibit bacteria growth) and incubated at $25^{\circ} \mathrm{C}$ for 5 to 10 days and examined for fungal growth. Identification of fungal isolates was carried out by examining the morphology and microscopic features (Dugan, 2006) using the microscope model Boeco, Germany.

Morphological examination included growth rate, general topography, surface and reverse pigmentation if any. Microscopic identification of positive fungal cultures was carried out using the method described by Murray et al. (2005). Briefly, a drop of lactophenol cotton blue dye was placed on a clean glass slide; a portion of the fungal culture was transferred into the lactophenol cotton blue dye and teased with a 22 gauge nichrome needle to separate the hyphae. The coverslip was placed on the preparation and examined under low and high power magnification using reduced light for identification. Microscopic characteristic of fungi such as hyphae, conidial heads and arrangements of conidia were observed. Slide culture was carried out on those isolates whose identification was inconclusive after staining with lactophenol cotton blue (Domsch et al., 2007).

\section{Data analysis}

Data generated from this work was presented in proportion and tables using Excel software (2007). Chi-square with contingency tables was used to analyze the data.

\section{RESULTS}

The sampled diseased $C$. gariepinus were characterized by skin ulcer, fin rot and tail rot (Figure 1" = A, B and C) while the apparently healthy $C$. gariepinus showed no clinical lesions. All the samples from the affected fish and apparently healthy fish were positive for multiple fungal growths after culture for 5 to 10 days and all isolates grew well on SDA incorporated with chloramphenicol except the dermatophytes that took up to ten days before any growths became visible. Occurrences of fungi in diseased and apparently healthy $C$. gariepinus were recorded in Tables 1 and 2. Morphologic and microscopic characteristics of various fungal species were shown in Figures 2 to 8.

Of the one hundred ninety eight (198) fungal isolates from 78 samples of skin and gills of diseased C. gariepinus, 26 (13.1\%), Aspergillus fumigatus, 25(12.6\%), A. flavus, 36 (18.1\%), Aspergillus niger, 37 (18.7\%), Penicillium species, 14 (7.1\%) Mucor species, 4 (2.0\%) for Rhizopus species, 14 (7.1\%), Trichophyton $\mathrm{sp}$. , and $42(21.2 \%)$ yeast isolates were isolated (Table 1).

A total of three hundred and ninety two (392) fungal isolates were recovered from the skin and gills of 178 apparently healthy $C$. gariepinus of which were 73 (18.6\%) Aspergillus fumigatus, 53 (13.5\%) A. flavus, 57 (14.5\%) A. niger, 1 (0.25\%) A. parasiticus, 4 5(11.55\%) Penicillium sp., 38 (9.7\%) Mucor species, 6(1.5\%) Rhizopus sp. and 119 (30.4\%) yeast (Table 2).

Aspergillus sp. was isolated from the two groups of fish as the predominant species. Aflatoxin-producing $A$. parasiticus and $A$. flavus were also isolated with $A$. flavus been the major sp. while $A$. parasiticus been the least. Similar isolates were recovered from skin and the gills of the two groups of fish except for $A$. parasiticus and Trichophyton sp. that were isolated from apparently healthy and diseased fish, respectively.

\section{DISCUSSION}

The fungal organisms isolated from diseased and apparently healthy fish in this research were somewhat similar. This was expected, as Aspergillus sp., Mucor sp., 

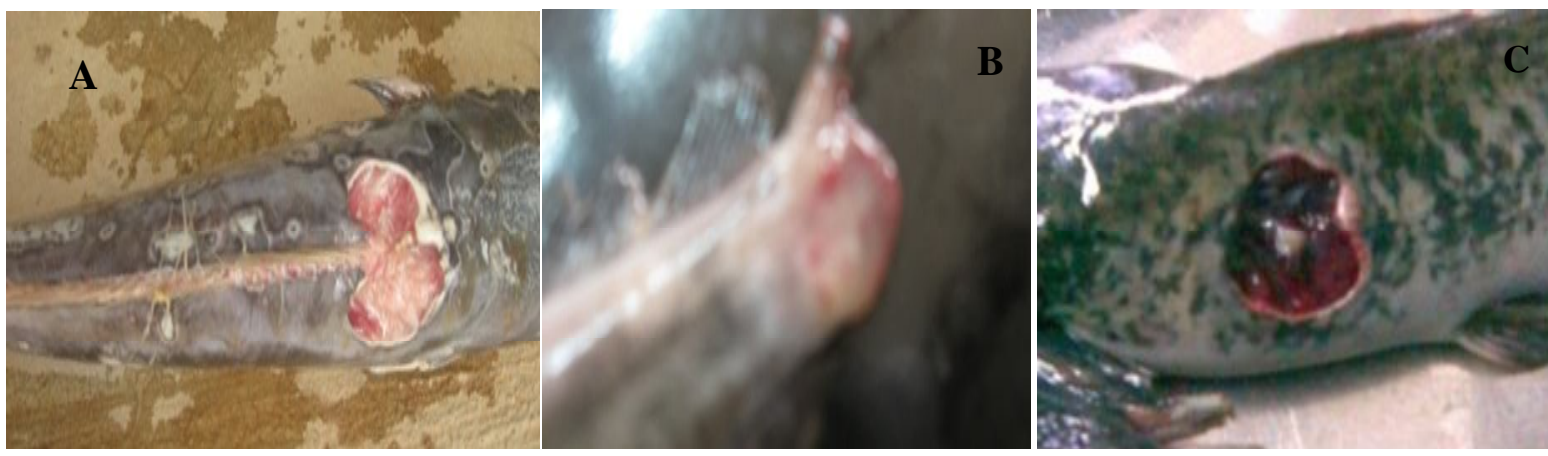

Figure 1. $A=$ ulcer and fin rot, $B=$ Caudal fin rot or tail rot, $C=$ Skin ulcer.

Table 1. Rate of fungal occurrence on the skin and gills of diseased Clarias gariepinus from Zaria, Kaduna State $(P>0.05)$.

\begin{tabular}{lcccc}
\hline Isolates & Skin no. & Gills no. & Total (No.) & Percentages (\%) \\
\hline A. fumigatus & 13 & 13 & 26 & 13.1 \\
A. flavus & 12 & 13 & 25 & 12.6 \\
A. niger & 19 & 17 & 36 & 18.2 \\
Penicillium sp. & 15 & 22 & 37 & 18.7 \\
Mucor sp. & 9 & 6 & 14 & 7.1 \\
Rhizopus sp. & 1 & 3 & 4 & 2.0 \\
Trichophyton sp. & 5 & 9 & 14 & 7.1 \\
Yeast & 23 & 19 & 42 & 21.2 \\
Total & 97 & 102 & 198 & 100 \\
\hline
\end{tabular}

$\mathrm{X}^{2}=4.48, \mathrm{df}=7, \mathrm{P}=0.72$.

Table 2. Rate of fungal occurrence on the skin and gills of apparently healthy Clarias gariepinus from Zaria, Kaduna State $(P>0.05)$.

\begin{tabular}{lcccc}
\hline Isolates & Skin no. & Gills no. & Total (No.) & Percentages (\%) \\
\hline A. fumigatus & 35 & 38 & 73 & 18.6 \\
A. flavus & 22 & 31 & 53 & 13.5 \\
A. niger & 29 & 28 & 57 & 14.5 \\
A. parasiticus & 0 & 1 & 1 & 0.3 \\
Penicillium sp. & 23 & 22 & 45 & 11.5 \\
Mucor sp. & 19 & 19 & 38 & 9.7 \\
Rhizopus sp. & 4 & 2 & 6 & 1.5 \\
Yeast & 62 & 57 & 119 & 30.4 \\
Total & 195 & 197 & 392 & 100 \\
\hline
\end{tabular}

$\mathrm{X}^{2}=4.13, \mathrm{df}=7, \mathrm{P}=0.76$.

Penicillium sp. and Rhizopus sp. were categorized by Refai et al. (2010) as normal mycobiota of freshwater fish. Even though these isolates are normal mycobiota of both Clarias and Tilapia, they can, however, produce disease because they are opportunistic fungi and many of them possess virulence factors, which enable them to cause diseases (Refai et al., 2004) especially under favourable predisposing condition. This finding agrees with the reports of other investigators that fungal infections are among the most serious types of disease problems in all types of aquaculture facility causing economic losses in fish farming in tropical Africa, and in other developing countries (Meyer, 1991). Several studies have documented several fungal agents associated with freshwater fish in Nigeria and all over the world. Christianah and Fagade (2010) while evaluating 

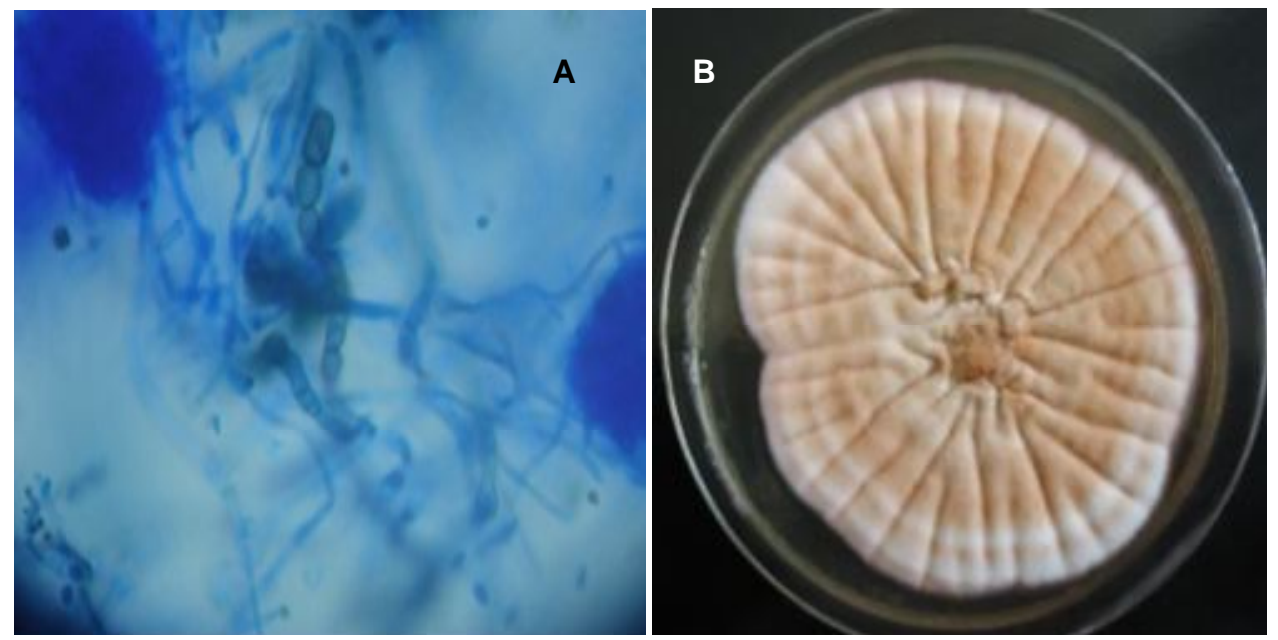

Figure 2. $A=$ Microscopic view ( $\times 40$ magnification) of Trichophyton $\mathrm{sp} . \mathrm{B}=$ Culture of Trichophyton sp on SDA.

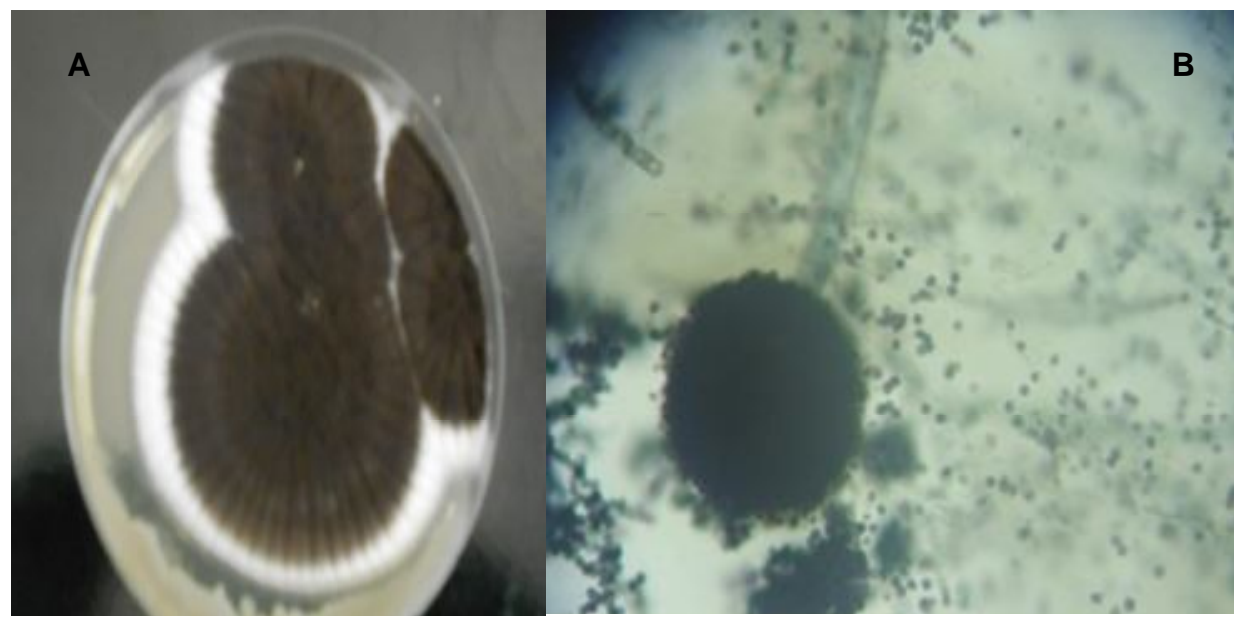

Figure 3. $\mathrm{A}=$ Culture of Aspergillus niger on SDA. $\mathrm{B}=$ microscopic view ( $\times 40$ magnification) of Aspergillus niger.

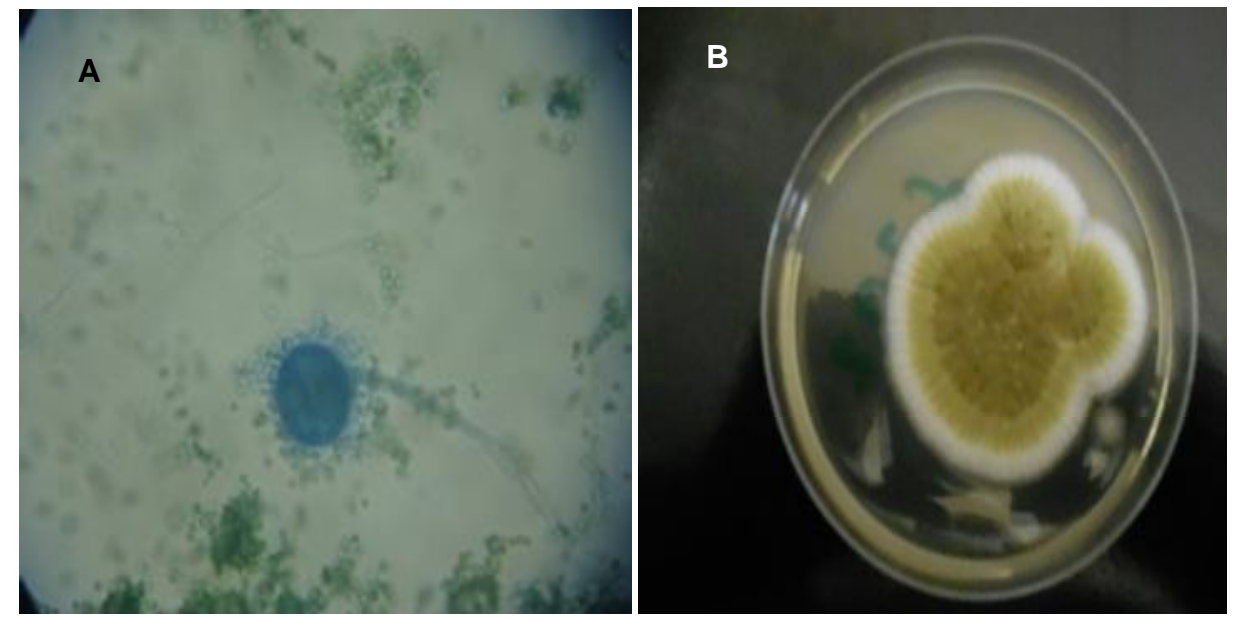

Figure 4. $\mathrm{A}=$ Microscopic view ( $\times 40$ magnification) of Aspergillus flavus. $\mathrm{B}=$ culture of $A$. flavus on SDA. 

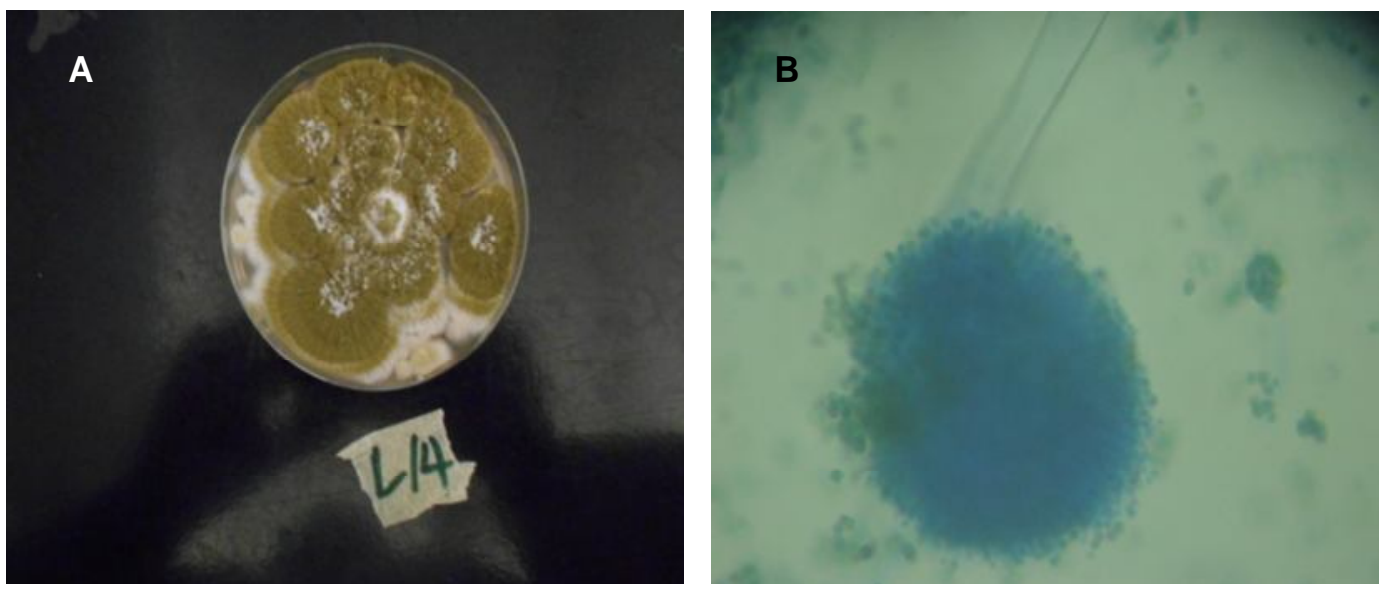

Figure 5. $\mathrm{A}=$ Culture of Aspergillus parasiticus on SDA. $\mathrm{B}=$ Microscopic view ( $\times 40$ magnification) of $A$. parasiticus.
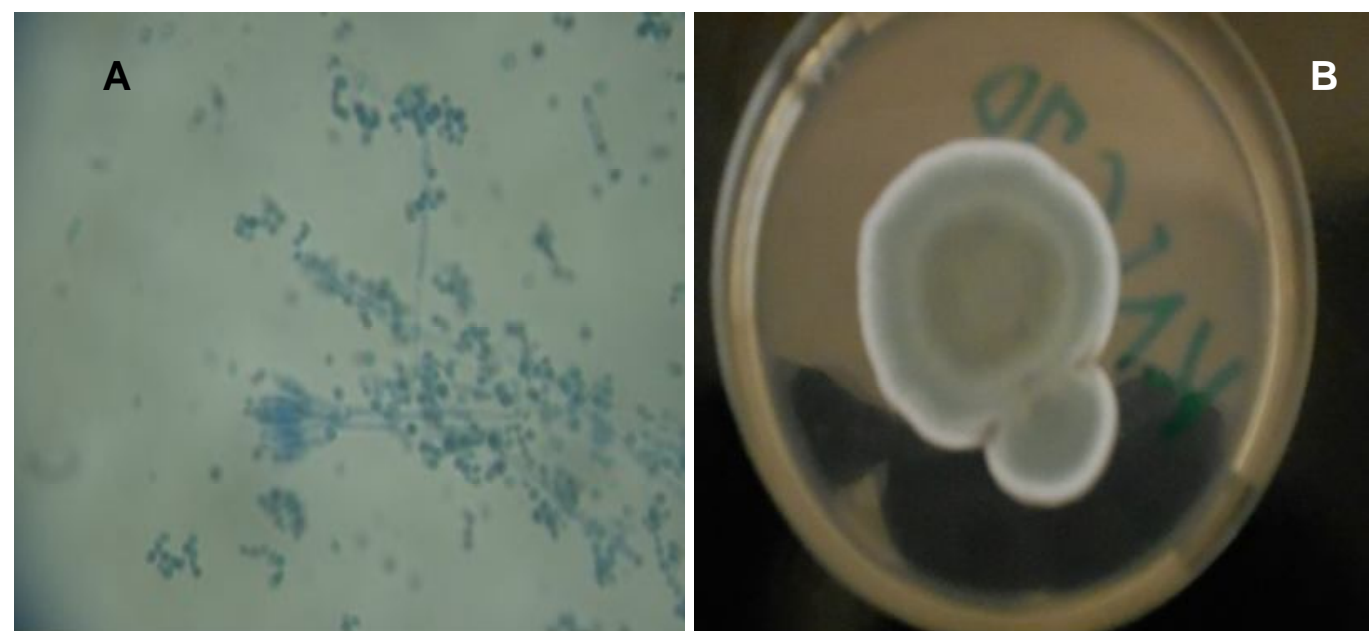

Figure 6. $\mathrm{A}=$ Microscopic view of Penicillium sp. $(\times 40) . \mathrm{B}=$ Culture of Penicillium sp. on SDA.

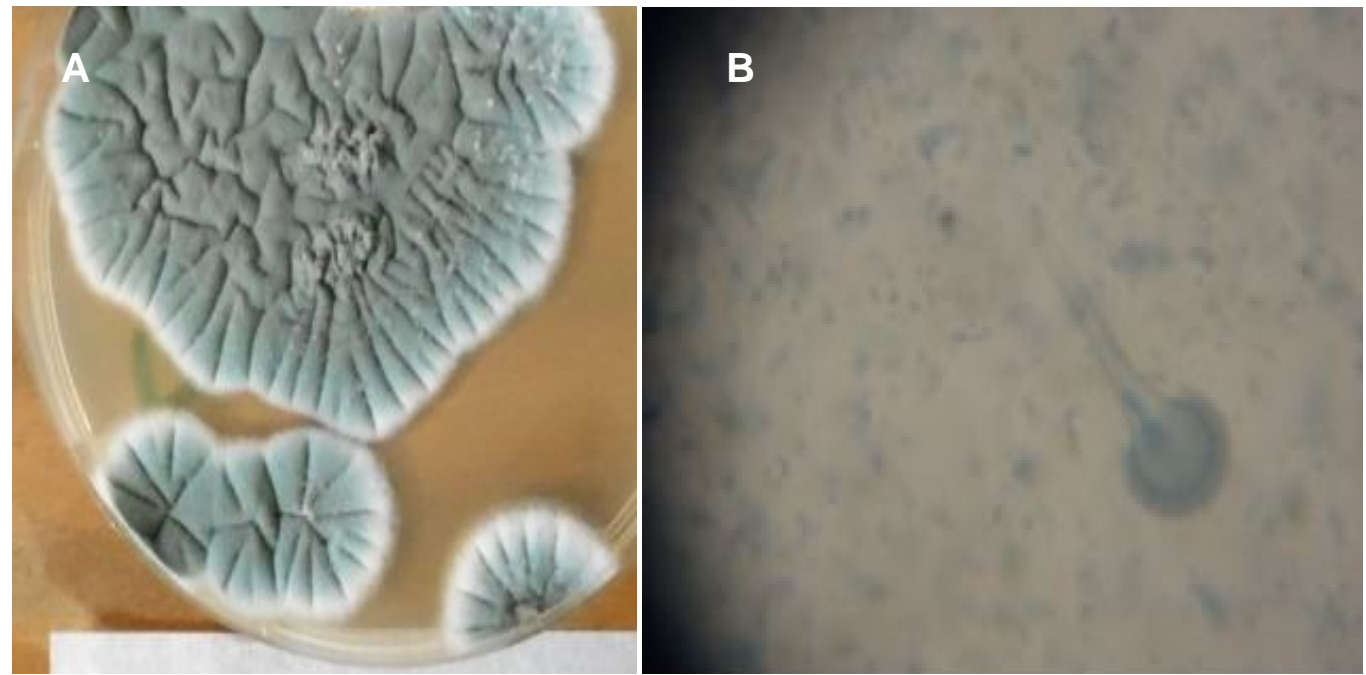

Figure 7. $\mathrm{A}=$ Culture of Aspergillus fumigatus on SDA. $\mathrm{B}=$ Microscopic view of Aspergillus fumigatus (×40), Microscope model, Boeco Germany. 

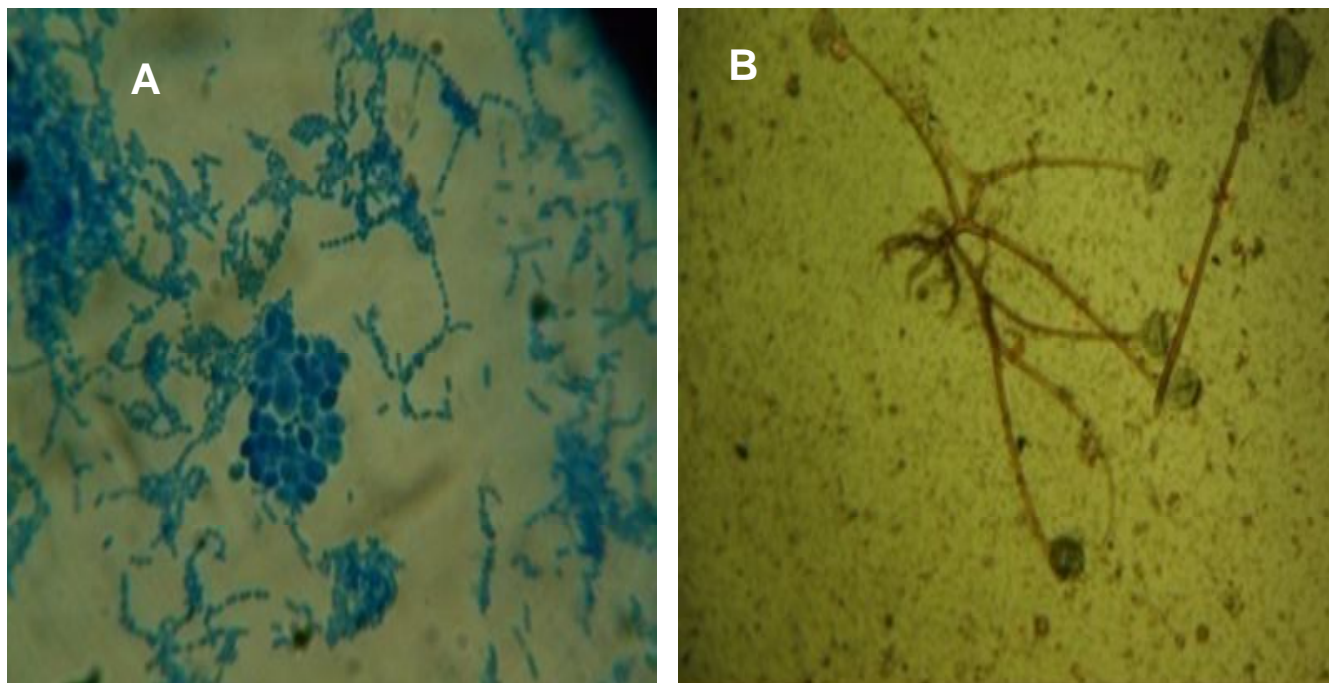

Figure 8. $A=$ Microscopic view of yeast, $B=$ Microscopic view of Rhizopus sp. both at $x 40$ magnification.

smoked fish (Ethmalosa fimbriata) from retail outlets in Ago-Iwoye, Ogun State, Nigeria for fungal contamination isolated the genera Aspergillus, Rhizopus and Penicillium as the predominant isolates. All isolates were said to degrade the proteins of the fish with $A$. ochraceous having the highest rate of degradation followed by $A$. niger and A. flavus. Tsadu et al. (2006), in his survey of fungi contaminating some species of fish from Tagwai dam Minna Niger state, isolated Aspergillus niger, A. flavus, A. parasiticus, A. fumigatus, Rhizopus sp., Mucors sp., Microsporum canis, Penicillum viridicalium and Fusarium sp from the skin, gills and fins of fish with $A$. niger contaminating all species of the fish sampled. Fafioye et al. (2008) isolated Aspergillus sp., Rhizopus sp., Fusarium sp. and Mucor sp., from smoked-dried four species of freshwater fish obtained from Oja-Oba market, Ago-Iwoye in Ogun state with Aspergillus sp. as the most prevalent species isolated. Rashmi and Chandan (2015) isolated Mucor sp., Rhizopus sp., Chaetomium globosum, Alternaria tenuis, Verticillium sp., Aspergillus fumigates, Penicillium funiculosum from some economically important freshwater fishes in Gandak River near Muzaffarpur region of Bihar. Mohamed (2011) isolated mycotoxin producing fungi: Aspergillus flavus, $A$. clavatus, A. ochraceous, A. parasiticus, A. terreus, A. vesicolor, Penicillium chrysogenum and Trichoderma viride from five fish species including tilapia and catfish growing in aquaculture.

The fungal organisms isolated in this study have been documented to be associated with $C$. gariepinus and Oreochromis niloticus. Abolude et al. (2013) isolated Penicillium sp., Acreomonium sp., Fusarium solani, Aspergillus sp., Mucor sp., and Saprolegnia sp. from eggs and brood stocks of Clarias gariepinus from hatchery farms in Zaria in Kaduna State, while Refai et al. (2010) isolated A. fumigatus, A. niger, A. terreus, $A$. flavus, Penicillium sp., Mucor sp., Rhizopus sp., Fusarium sp. and Saprolegnia sp. from diseased and apparently healthy $C$. gariepinus and $O$. niloticus in a study to assess mycotic settlement of freshwater fish in Egypt. Most of the fungal isolates gotten from this research are of veterinary and medical importance (BeckSague and Jarvis, 1993; Denning, 1996).

The results of this study showed that all diseased and apparently healthy fish sampled were positive for multiple fungal organisms; this may be due to the opportunistic nature of most of the fungi. Isolation of the fungal agents from diseased and apparently healthy fish meant for human consumption in this study suggests that mycosis may be a major disease of $C$. gariepinus in Zaria areas and that the fungi isolated from this work might have been responsible for the lesions/disease conditions noticed on the fish or they might have occurred secondary to bacterial or viral infection.

The result of this study demonstrated that infection of C. gariepinus with any of these fungal agents may result in the ulcer, fin rot and tail rot. The identification of the fungal organisms in this study was by culture, slide culture, Gram's staining and staining using lactophenol cotton blue. Isolation of fungal organism from the gills of fish may predispose the fish to respiratory disease (Srivastava, 2009).

Most of the fungal isolates in this research were from the genus Aspergillus; $A$. fumigatus, A. flavus, A. niger and $A$. parasiticus. Isolation of Aspergillus spp. as the major isolates from this study is significant because Aspergillus sp. have been documented to be associated with the disease outbreak in fish culture. $A$. niger is a human pathogen and environmental contaminant and $A$. fumigatus has been identified as important agents of nosocomial fungal infections and implicated as been responsible for life-threatening pulmonary disease of 
animal and immuno-compromised human in the world (Denning, 1996). Isolation of $A$. flavus and $A$. parasiticus in this study may predispose fish to aflatoxin contamination and consumers to aflatoxicosis if the fish are consumed by man because they are responsible for aflatoxins production (Ghadeer and Al-Delamiy, 2012).

Many researchers categorised many of the isolates as normal mycobiota, however isolation of these agents from diseased as well as from apparently healthy fish signify they might have been responsible for the infections noticed on the fish or they might have colonized the fish secondary to bacterial organisms, because ulcer, tail rot and fin rot are found to be associated with infections caused by bacteria Aeromonas sp. and Pseudomonas sp. (Jawahar et al., 2004). C. gariepinus from Zaria area may serve as the reservoir for the fungal agents isolated and subsequently become the route through which they reach the human population that consume or and handle the fish. Fungal organisms isolated from diseased and apparently healthy fish might not be pathogenic to apparently healthy fish but may cause disease in stressed and immune compromised fish. These isolates may, however, induce diseases in man when the fish are consumed.

Fungi organisms isolated from apparently healthy and diseased C. gariepinus in this study are similar and may be part of normal mycobiota of this fish in Zaria areas, but at the same time might have been responsible for the diseased condition noticed on the fish and subsequently may cause morbidity and mortality in catfish culture. These isolates may have arisen secondary to bacterial, parasitic or viral infection. The fungi organism isolated might have been introduced from the environment or through contaminated fish feeds because these fungal species are reported to be infectious through contamination of fish feeds (Saleem et al., 2012). Also these agents might have been introduced to the ponds from the poultry units by the attendants because all the farms practiced mixed farming and so it is easy for these isolates to be spread either by the attendants or by the wind dispersing the spores. Isolation of some of these isolates from fish in this study might make their consumption hazardous to human health.

\section{Conclusion}

This study to investigate fungal organisms associated with apparently healthy and diseased $C$. gariepinus from fish farm in Zaria, Kaduna State, Nigeria isolated and identified eight different fungi species and several yeast isolates from skin, gills and gut of the fish. Identification of the fungi was based on morphologies and with the help of authentic manuals of fungi. The most common species of fungi isolated from diseased and apparently healthy $C$. gariepinus were Aspergillus sp., Trichophyton sp., Penicillium sp. and Mucor sp. and yeast isolates. Similar fungal organisms were isolated from diseased and apparently healthy fish. Potential aflatoxin producing species of fungi were isolated from diseased and apparently healthy fish meant for human consumption. Infection of $C$. gariepinus with any of these fungal organisms may result in ulcer, fin rot and tail rot thereby result in economic loss to the farmer as they rendered the fish unmarketable. Fungal organisms isolated may be part of mycobiota of $C$. gariepinus or they may take part in disease of the fish in Zaria, they may also be source of fungal infection and aflatoxicosis when fish are consumed. It is recommended that further study is carried out to determine the role play by individual specie of fungi in Clarias diseases, morbidity and mortality. There is the need to study individual fungus and their role in fish diseases in sampled area and in the country as a whole with a view to instituting preventive and control measures. It is recommended that periodic examination of fishes grown in aquacultures in Zaria is carried out to ensure that they are devoid of fungal contamination to conserve public health. Aflatoxin level in the fish raised in the culture in Zaria should be quantified to ensure they are not above the limit allowable for the human. Duties should be assigned on integrated farm to prevent spread of pathogenic organisms from one production unit to another.

\section{REFERENCES}

Abolude DS, Opabunmi OO, Davies OA, 2013. Fresh water fungi associated with eggs and broodstock of African catfish (Clarias Gariepinus, Burchell 1822) in fish hatchery farms, Zaria, Kaduna State, Nigeria. J Res Envi Sci Toxic, 2(7): 131-135.

Adesulu EA, Olaleye WF, Akinpelu Al, 2004. Pisciculture Essential Production Information. University of Ibadan Press, Ibadan, Nigeria. pp: 10-25.

Anderson B, Thrane $U$, 2006. Food-borne fungi in Fruit and Cereals and their production of mycotoxins. In: Hocking $A D$, Samson RA, Pitt JI \& Thrane U. (eds) Advan in Food Mycol. Springer. USA, 137-152.

Beck-Sague C, Jarvis WR, 1993. Secular trends in the epidemiology of nosocomial fungal infections in the United States, 1980-1990. National Nosocomial Infections Surveillance System. J Infec Dis, 167: 1247-1251.

CAST, 2003. (Council for Agricultural Science and Technology) Mycotoxins: risk in plant, animal, and human systems. CAST, Ames, lowa, USA. Task Force Report no. 139, 199 pp.

Christianah IA, Fagade OE, 2010. Mycological Evaluation of Smoked Fish from the Retail Outlets in Ago-Iwoye, Ogun State, Nigeria. J Life Phys Sci, 3(2): 65-66.

Denning DW, 1996. Therapeutic outcome in invasive Aspergillosis. Clin Infect Dis, 26: 781-805.

Domsch KH, Gams W, Anderson TH, 2007. Compendium of soil fungi. 2nd taxonomically revised edition by W. Gams. IHW, Eching.

Douglas LP, Ayala CE, Guzman-Perez SE, Lopez-Garcia R, Trujillo S, 2000. Microbial Toxins in Foods: Algal, Fungal, and Bacterial.

Dugan FM, 2006. The identification of fungi.An illustrated introduction with keys, glossary, and guide to literature. The Ameri Phytopatholo Socie, St. Paul, Minnesota, USA, 176 p. ISBN 0-98054-336-4.

Efuntoye MO, Olurin KB, Jegede GC, 2012. Bacterial Flora from Healthy Clarias Gariepinus and their Antimicrobial Resistance Pattern. Adv J Food Sci Technol, 4(3): 121-125.

Fafioye $\mathrm{OO}$, Fagbohun TR, Olubanjo OO, 2008. Fungal infestation and nutrient quality of traditionally smoke dried freshwater fish. Turk $\mathrm{J}$ Fisheries Aquatic Sci, 8: 8-9.

FDF, 2007. Fishery Statistics of Nigeria. Department of Fisheries Publication, FCT, Abuja, Nigeria, pp: 11-24. 
Ghadeer AO, Al-Delamiy KS, 2012. Aflatoxin B1 production by Aspergillus flavus in different media and containeers and the antifungal activity of garlic and black cumin. Res J Engineer Appl Sci, 1: 117-121.

Jawahar AT, Debasis S, Tirthankar B, 2004. Bacterial flora associated with diseased fish and their Antibiogram. J Indian Fisheries Assoc, 31: 177-180.

Meyer FP, 1991. Aquaculture disease and health management. J Anim Sci, 69: 4201-208.

Mohamed $\mathrm{H}$, 2011. Isolation of mycotoxin-producing fungi from fishes growing in Aquaculture. Res J Microbiol, 6: 862-872.

Murray PR, Rosenthal KS, Pfaller MA 2005. Superficial and cutaneous mycosis. In: Medical Microbiology, 5th edition, Philadelphia, USA, 745-751.

Nkemakolam AN, Ebenezer DO, Aimuanmwosa FE, 2011. Application of probiotics in Nigeria aquaculture: Current status, challenges and prospects. Int Res J Microbiol, 2(7): 215-219.

Olaosebikan BD, Raji A, 1998. Nigeria fresh water fishes. Federal college of freshwater fisheries technology, New Bussa, Nigeria. 106p.

Olojo EAA, Amusa NA, Osho A, Badejo VO, 2010. Commensal bacterial flora of Syndontis nigrita Clarias gariepinus from River Osun, Southwest Nigeria, Nigeria. Res J Appl Sci, 5(3): 231-235.

Quiniou SMA, Bigler S, Clem LW, 1998. Effects of water temperature on mucous cell distribution in channel catfish epidermis: a factor in winter saprolegniasis. Fish Shellf Immunol, 8:1-11.

Rashmi K, Chandan K, 2015. Fungal infection in some economically important freshwater fishes in Gandak River near Muzaffarpur Region of Bihar. Int J Life Sci Pharm Res, 5:L1-L11.

Refai MK, Attia S, Salem RM, EIDahshan EM, 2004. Studies on the pathogenicity of Aspergillus fumigatus, $A$. flavus and $A$. niger isolated from chickens and their environment. Egypt. J Comp Path Clinic Path, 17(2): 193-205.

Refai MK, Laila AM, Amany, MK, Shimaa, El-SMA, 2010. The assessment of mycotic settlement of freshwater fishes in Egypt. J Am Sci, 6(11): 823-831.

Robert RJ, 1989. The Pathophysiological and Systemic Pathology of Teleost. In R.J. Roberts (ed.). Fish pathol. Bailliere Tindall, London, England. p. 56-134.

Saleem MJ, Hanan A, Nisa AU, Qasir TA, 2012. Occurrence of aflotoxinin maize seed under different condition. Int $\mathrm{J}$ Agric Biol, 14: 473-476.

Srivastava RC, 2009. Fish Mycopath. Today and tomorrow's Publishers New Dehli, India. p. 106.

Tsadu SM, Ojutiku RO, Ayanwale AV, 2006. Survey of fungal infestation of some fish species from Tagwai dam, Minna, Niger State. In: 19th Annual Conference of the Fisheries Society of Nigeria (FISON), 29 Nov - 03 Dec 2004, llorin, Nigeria. J Trop Biosci, 6: 1-5.
Citation: Salawudeen MT, Kazeem HM, Raji MA, Oniye SJ, Kwanashie CN, Ibrahim MJ, 2017. Isolation and identification of fungi from apparently healthy and diseased Clarias gariepinus from freshwater in Zaria, Kaduna State, Nigeria. Microbiol Res Int, 5(1): 8-15. 